Making Research Accessible to Marginalised and Vulnerable Groups

\title{
013 PP COLLABORATION WITH D/DEAF PEOPLE IN A HEARING CENTRIC WORLD
}

D Ferndale. Statewide Deafness and Mental Health Consultation and Liaison Service, Queensland Health, Australia; School of Psychology, University of Queensland, Australia

10.1136/bmjopen-2017-016492.31

Researchers operate in highly complex and dynamic contexts. Collaborative approaches to research, while enriching, introduce 
new layers of complexity and challenges that require critical reflection. In doing research in the field of $d / D e a f$ studies, this could not be more depictive of my experience. The $d /$ Deaf community in Australia have a strong and rich culture and a complex expressive language. This community has a long history of hearing people oppressing their culture and this continues to shape $\mathrm{d} /$ Deaf and hearing relations and $\mathrm{d} /$ Deaf people's experiences of education and opportunity. Collaborative approaches to $\mathrm{d} /$ Deaf research require members of the research team to consider linguistic accessibility (and logistics of ensuring accessibility) and power relations, as well as the epistemological and ontological assumptions underpinning research design, methodology, data collection and reporting. Often times the priorities of funding bodies and university institutions are not in line with the research goals of the team or the individuals within the team. More than this, there is rarely an acknowledgement or a discussion about each person's ontological and epistemological approach to research, and how this might conflict or be managed. In this presentation, I visually illustrate critical reflections collaborative approaches to research in the mainstream context and in $\mathrm{d} /$ Deaf studies, prompting discussion about the layers of complexity and challenges associated with collaborative research. 